\title{
Effect of dead volume on the efficiency and the cost to deliver medications in cystic fibrosis with four disposable nebulizers
}

\author{
Sharon L Ho BSc RRT, Allan L Coates MD CM \\ Divisions of Respiratory Medicine and Lung Biology Research, The Hospital for Sick Children, \\ Research Institute, and the University of Toronto, Toronto, Ontario
}

SL Ho, AL Coates. Effect of dead volume on the efficiency and the cost to deliver medications in cystic fibrosis with four disposable nebulizers. Can Respir $\mathbf{J}$ 1999;6(3):253-260.

OBJECTIVES: To evaluate the factors that affect nebulizer efficiency and to compare the relative cost effectiveness of nebulized medications used in the treatment of cystic fibrosis (CF), delivered by four types of disposable jet nebulizers that are widely used in hospitals.

DESIGN: The Hudson 1730 Updraft II, Baxter Misty-Neb, Marquest Whisper Jet (WJ), and Marquest Acorn II were evaluated in terms of respirable aerosol output (particles $5 \mu \mathrm{m}$ or less), nebulizer dead (residual) volume $\left(\mathrm{V}_{\mathrm{D}}\right)$, and time for complete nebulization using saline, salbutamol and tobramycin at flows of 6 and $8 \mathrm{~L} / \mathrm{min}$. The respirable fraction (RF) was determined by laser diffraction, and drug output was calculated from the initial volume and concentration of the drug in the nebulizer minus the product of final drug concentration and the $\mathrm{V}_{\mathrm{D}}$ following nebulization.

COST ANALYSIS: The expected pulmonary deposition $\left(D_{E}\right)$ was estimated, and incorporated with the material and labour costs to determine the cost effectiveness of each type of nebulizer.

RESULTS: With a DE greater than two times that of the WJ at a cost of 2.4 times less, the Updraft II proved most efficient and cost effective of all the nebulizers evaluated in this study. CONCLUSIONS: The cost effectiveness of each nebulizer was determined by its efficiency, which in turn was predominantly related to its $\mathrm{V}_{\mathrm{D}}$ and $\mathrm{RF}$ at each flow. The efficiencies of these four devices were different and could not have been predicted from specifications provided by the respective manufacturers.

Key Words: Aerosol; Cost effectiveness; Cystic fibrosis; Dead volume; Efficiency; Nebulizer

Effet de l'espace mort sur la performance et le coût de l'administration de médicaments aux patients atteints de fibrose kystique du pancréas avec quatre nébuliseurs jetables

OBJECTIFS : Évaluer les facteurs qui modifient la performance d'un nébuliseur et comparer la rentabilité relative des médicaments nébulisés et utilisés pour traiter la fibrose kystique du pancréas (FKP) au moyen de quatre types de nébuliseurs jetables largement utilisés dans les hôpitaux.

MODĖLE : Les nébuliseurs Hudson 1730 Updraft II, Baxter Misty-Neb, Marquest Whisper Jet (WJ) et Marquest Acorn II ont été évalués relativement à leur production de gouttelettes respirables (particules de $5 \mu \mathrm{m}$ et moins), à l'espace mort $\left(\mathrm{V}_{\mathrm{D}}\right)$ résiduel du nébuliseur, et au temps requis pour une nébuli-

voir page suivante 
sation complète de salin, de salbutamol et de tobramycine à des débits de 6 et $8 \mathrm{~L} /$ minute. La fraction respirable (FR) a été déterminée par diffraction d'un laser, et l'émission du médicament a été calculée à partir du volume initial et de la concentration du médicament dans le nébuliseur moins le produit de la concentration finale de médicament et le $V_{D}$ après la nébulisation.

ANALYSE DU COÛT : Le dépôt pulmonaire théorique $\left(D_{E}\right)$ a été estimé puis incorporé au coût de la main-d'œuvre et du matériel pour déterminer la rentabilité de chaque type de nébuliseur.
RÉSULTATS : Avec une $\mathrm{D}_{\mathrm{E}}$ deux fois plus élevée que celle obtenue avec le WJ à un coût 2,4 fois moins important, le Updraft II s'est révélé le plus efficace et le plus rentable de tous les nébuliseurs évalués dans la présente étude.

CONCLUSIONS : La rentabilité de chaque nébuliseur a été déterminée d'après sa performance, qui à son tour était principalement liée à son $\mathrm{V}_{\mathrm{D}}$ et à sa $\mathrm{FR}$ à chaque débit. Les performances de ces quatre appareils étaient différentes et n'auraient pas pu être prévues à partir des spécifications fournies par les fabricants respectifs.
$I^{\prime}$ nhalational aerosol therapy is widely used as a method to deliver bronchodilators and antibiotics in the treatment of cystic fibrosis (CF). It is commonly accepted that the ideal particle size for pulmonary deposition at the level of the lower airways is within the range of 1 and $5 \mu \mathrm{m}$ in diameter, and, from this concept, the respirable fraction (RF) of aerosol output has been defined as the mass of drug carried in droplets $5 \mu \mathrm{m}$ or less (1-3), although it is recognized that data in the pediatric age group are limited and in vitro data may not correlate with in vivo data (4). While the combination of particle size distribution, gas flow driving the nebulizer and the fill volume is recognized as a factor that contributes to nebulizer efficiency and performance (3), these considerations are often not taken into account when making institutional purchasing decisions. The effects of dead volume $\left(\mathrm{V}_{\mathrm{D}}\right)$, the volume of solution remaining in the nebulizer at the end of nebulization, has not been adequately studied with regards to the efficiency of a nebulizer. Conceptually, if a nebulizer is filled with a highly concentrated drug with a total charge volume only slightly larger than the inherent $\mathrm{V}_{\mathrm{D}}$ of that device, little drug will be aerosolized. Another issue not often considered when evaluating output characteristics is the effect of evaporative losses during the nebulization process and the resultant concentration of the initial solution. It is known that using gravimetric methods alone to calculate aerosolized drug output can lead to significant error (5-8), especially when using a dry gas source (9-11), as is common in many hospital settings.

The reusable breath-enhanced type of nebulizers such as the LC Jet Plus (Pari Respiratory Equipment Inc, Midlothian, Virginia), the LC Star (Pari Respiratory Equipment Inc) and the Medic-Aid Ventstream (Medic-Aid Ltd, Pagham, United Kingdom) have been shown to be more efficient in vitro (12) and in vivo (13); however, they are predominantly limited to home use. This is largely because of the issues surrounding sterilization processes for in hospital use, and the significant cost of these reusable (compared with disposable) devices has led to widespread use of standard disposable nebulizers in hospitals. Many clinicians and purchasing agents have assumed that the various brands of nebulizers available are comparable in their capacity to generate and deliver therapeutic aerosols, despite several studies suggesting the contrary $(1,6,14,15)$. In a cost-conscious health care environment, the unit price is a major determining factor for bulk purchases made by hospital purchasing agents (personal communication).
Seven institutions affiliated with the University of Toronto were surveyed before this study, and none was using the reusable breath-enhanced nebulizers. We, therefore, focused our evaluation on four types of disposable jet nebulizers to reflect the current practices of these hospitals. At The Hospital for Sick Children, Toronto, Ontario, 6996 nebulizers were purchased over the previous 12 months, and the number of aerosol treatments (although not on hospital records) likely exceed this number by approximately four to five times because each disposable nebulizer is used for several administrations for each patient.

In this study, we investigated the effects of $V_{D}, R F$ and flow through the nebulizer on the efficiency of each device including the effects of evaporative losses while nebulizing medications commonly used to treat $\mathrm{CF}$ within a hospital setting. The cost effectiveness of each device was examined, taking into consideration the estimated pulmonary deposition for each brand of nebulizer, and the cost of medications, labour and the nebulizer.

\section{METHODS AND MATERIALS}

Of the seven Toronto hospitals surveyed; four institutions were using the Misty-Neb nebulizer (Baxter Healthcare Corp, Valencia, California); two institutions were using the Acorn II nebulizer (Marquest, Englewood, Colorado); and one institution was using the Whisper Jet nebulizer (Marquest) (WJ). The Hudson 1730 Updraft II nebulizer (Hudson, Temecula, California) was not in use in any of the institutions surveyed; however, it was chosen for this study because of its commercial availability. Previous work $(2,3,12)$ with this device indicated that it was a nebulizer of reasonable performance (more than 50\% of the output was in the RF [16]). Each of the nebulizers listed above are widely available throughout North America. Six nebulizers of each type were assessed in terms of $V_{D}, R F$, the drug output within the RF $\left(\mathrm{O}_{\mathrm{RF}}\right)$ and the time required to complete nebulization, using flows in the operating range recommended by each manufacturer. The driving gas was air from a 50 psi compressed dry gas source. To control inadequate 'back pressure compensation' $(2,3)$, the rotameter used was calibrated specifically for each device at the exit port of the nebulizer using a flow calibration instrument (Timeter RT200, Allied Health Care Products, St Louis, Missouri) to ensure accuracy of driving flows at 6 and $8 \mathrm{~L} / \mathrm{min}$. Because these nebulizers are designed as disposable units and not engineered to withstand repeated use, two sets of six of each type of nebulizer were 
selected. Each set was comparable with the others of its type in terms of particle size distribution and output for saline, as well as back pressure at flows of 6 and $8 \mathrm{~L} / \mathrm{min}$.

Standard pediatric doses of medications commonly administered by the aerosol route in the treatment of CF $(2,17)$ were used in the assessment of each type of nebulizer. The two drug regimens are outlined below:

- $0.5 \mathrm{~mL}(2.5 \mathrm{mg}$ ) salbutamol (Salbutamol Respirator Solution, $5 \mathrm{mg} / \mathrm{mL}$, PharmaScience Inc, Montreal, Quebec) with $3.5 \mathrm{~mL}$ of $0.9 \%$ saline solution; or

- $2 \mathrm{~mL}$ (80mg) tobramycin (Nebcin $40 \mathrm{mg} / \mathrm{mL}$, Eli Lilly Canada Inc, Scarborough, Ontario) with $2 \mathrm{~mL}$ of $0.9 \%$ saline solution.

The weight of each nebulizer was determined using an electronic balance (Metler PJ400, Fisher Scientific, Nepean, Ontario) to define the dry, and pre- and postnebulization weights. As outlined above, the total fill volume of each nebulizer was $4 \mathrm{~mL}$ (3) based on a unit density of $1 \mathrm{~g} / \mathrm{mL}$, prenebulization weight minus dry nebulizer weight equaled $4 \mathrm{~g}$ ). End nebulization was defined as the period of $30 \mathrm{con}-$ secutive seconds when no aerosol was generated $(1,6,18,19)$. $\mathrm{V}_{\mathrm{D}}$ was determined by subtracting the dry nebulizer weight from the postnebulization weight. The nebulized volume output of each nebulizer was determined by subtracting the postnebulization weight from the prenebulization weight. However, the nebulized volume output is not equivalent to the total nebulized drug output because the aerosol output is a combination of drug, water vapour and saline solution. Constant evaporation occurs and results in the concentration of the solution in the nebulizer during the nebulization process $(6,20-22)$. Because the total drug output rather than volume output is the concern, the evaporative losses were measured by the changes in osmolality of the solutions pre- and postnebulization by vapour pressure osmometry (model 5500, Wescor Inc, Logan, Utah). Osmolality ratios have been shown to reflect accurately concentration ratios of tobramycin and salbutamol (23). Thus, the drug concentration remaining in the $V_{D}$ postnebulization was calculated as $V_{D}$ times the initial drug concentration times the fraction of the osmolality postnebulization over prenebulization. The total nebulized drug output was then calculated by subtracting the amount of drug remaining in the $V_{D}$ from the initial drug dose at the start of nebulization.

\section{Summary of calculations}

$$
\text { Fill Volume }=\text { Weight }_{\text {pre }}-\text { Weight }_{d r y}
$$

( $4 \mathrm{~mL}$ for all nebulizers)

$$
\begin{gathered}
\text { Nebulized Volume Output }=\text { Weight }_{\text {pre }}-\text { Weight }_{\text {post }} \\
\qquad V_{D}=\text { Weight }_{\text {post }}-\text { Weight }_{\text {dry }} \\
\mathrm{O}_{\mathrm{T}}=\mathrm{D}_{\mathrm{i}}-\left(\mathrm{V}_{\mathrm{D}} \times \mathrm{C}_{\mathrm{i}}\right)\left(\text { osm }_{\text {post }} / \mathrm{osm}_{\text {pre }}\right)
\end{gathered}
$$

where weight was measured in grams; volume was based on a solution unit density of $1 \mathrm{~g} / \mathrm{mL}$; $\mathrm{O}_{\mathrm{T}}$ is the total nebulized drug output $(\mathrm{mg})$; $\mathrm{D}_{\mathrm{i}}$ is initial drug dose $(\mathrm{mg}) ; \mathrm{C}_{\mathrm{i}}$ is initial concentration of solution $(\mathrm{mg} / \mathrm{mL})$; osm $_{\text {post }}$ is the osmolality postnebulization $(\mathrm{mmol} / \mathrm{kg}$ ) and osm pre is the osmolality prenebulization $(\mathrm{mmol} / \mathrm{kg})$.

The particle size distribution of the aerosol droplets was measured by He-Ne laser diffractometry (Malvern Mastersizer X, Malvern Instruments, Worcestershire, United Kingdom) to avoid the effects of droplet drying often encountered with the use of cascade impaction $(24,25)$. Each nebulizer was vertically clamped, and the aerosol was directed through the laser beam at a distance of $24 \mathrm{~mm}$ from the face of the lens and $20 \mathrm{~mm}$ from the optical plane (24). Due to the latent heat loss during evaporation, the temperature of the nebulizing solution rapidly decreases from ambient to approximately $10^{\circ} \mathrm{C}$, and during this time the aerosol droplet size can be variable, but will remain constant once this temperature is reached until the end of nebulization (18). The particle size measurements were, thus, made at 2 mins from the start of nebulization, allowing for the temperature to reach equilibrium. The Mastersizer X uses the principle of Fourier optics to determine the pattern of light scattering as a cloud of aerosol is passed through the laser in front of a $100 \mathrm{~mm}$ receiving lens. Aerosol droplets diffract the light at an angle that is inversely proportional to the droplet size. The light diffracted through the lens is then captured on a photosensitive collector plate located at the focal length of the lens. The droplet size distribution can then be computed based on the intensity of light detected on each of the annular rings of the collector plate. The Mie Theory of light scattering was used to interpret the data generated because it accounts for the spherical transparent nature of the aerosol droplets. The actual drug content in each droplet is not measured using this technique but rather the diameter of the droplets from which volume can be calculated, and the mass of the drug contained in them is proportional to the volume. Larger droplets $(10 \mu \mathrm{m})$ contain more drug, but also have a lower probability of entering and depositing in the lung, while droplets with a diameter less than $5 \mu \mathrm{m}$ have a higher probability of entering and depositing in the targeted airways (1), although comparatively they carry less drug. RF was obtained from the measured particle size distribution, and the respirable drug output from the nebulizer was calculated using the following equation:

$$
\mathrm{O}_{\mathrm{RF}}=\mathrm{O}_{\mathrm{T}} \times \mathrm{RF}
$$

where $\mathrm{O}_{\mathrm{RF}}$ is the drug output within the respirable fraction (mg).

Product specifications for each brand of nebulizer were obtained from the respective manufacturers, and the authors attempted to predict each nebulizer's efficiency based solely on the literature provided. In the laboratory, the authors replicated the testing conditions identified by the specifications for each product and used the same testing solutions to generate comparable data.

Cost analysis: The analysis was based on the efficiency of each nebulizer, and included the cost of the medication, the device and the cost for the administration by a respiratory therapist. Nebulizer efficiency was defined as the percentage of the initial drug dose that was available as respirable aerosol from each type of nebulizer. To estimate the pulmonary drug deposition when using each type of nebulizer, some basic assumptions were made for the ease of relative interproduct comparisons. Given that these nebulizers are all constant output devices that will not alter output despite any pa- 


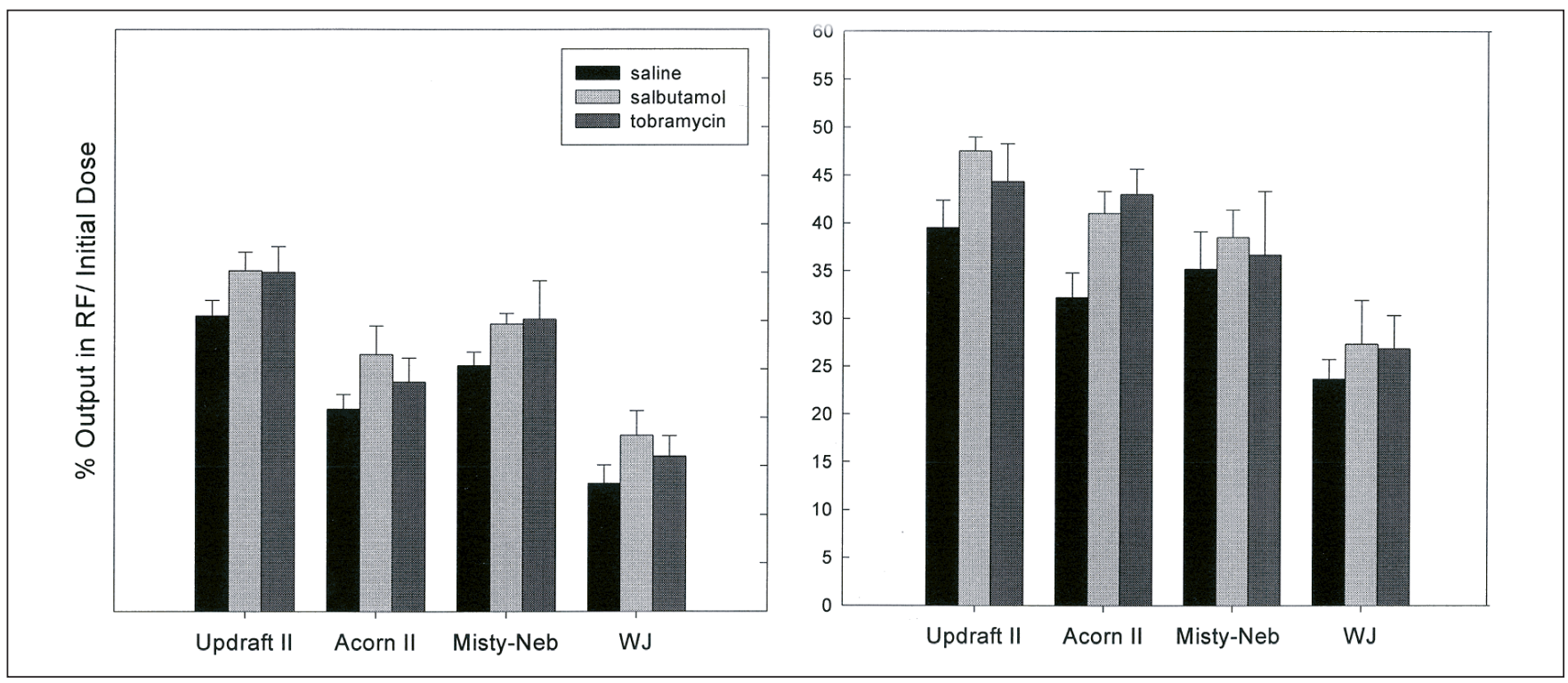

Figure 1) Left Mean efficiency within a $95 \%$ CI of each type of nebulizer for $4 \mathrm{~mL}$ of saline, and the $4 \mathrm{~mL}$ drug trials of salbutamol and tobramycin at a flow of $6 \mathrm{~L} / \mathrm{min}$. The efficiency for each nebulizer is expressed as a percentage of the initial drug dose, which is available as respirable aerosol output. Right Mean efficiency within a 95\% CI of each type of nebulizer for $4 \mathrm{~mL}$ of saline, and the $4 \mathrm{~mL}$ drug trials of salbutamol and tobramycin at a flow of $8 \mathrm{~L} / \mathrm{min}$. The efficiency for each nebulizer is expressed as a percentage of the initial drug dose, which is available as respirable aerosol output. RF Respirable fraction; WJ Whisper Jet nebulizer (Marquest, Englewood, Colorado)

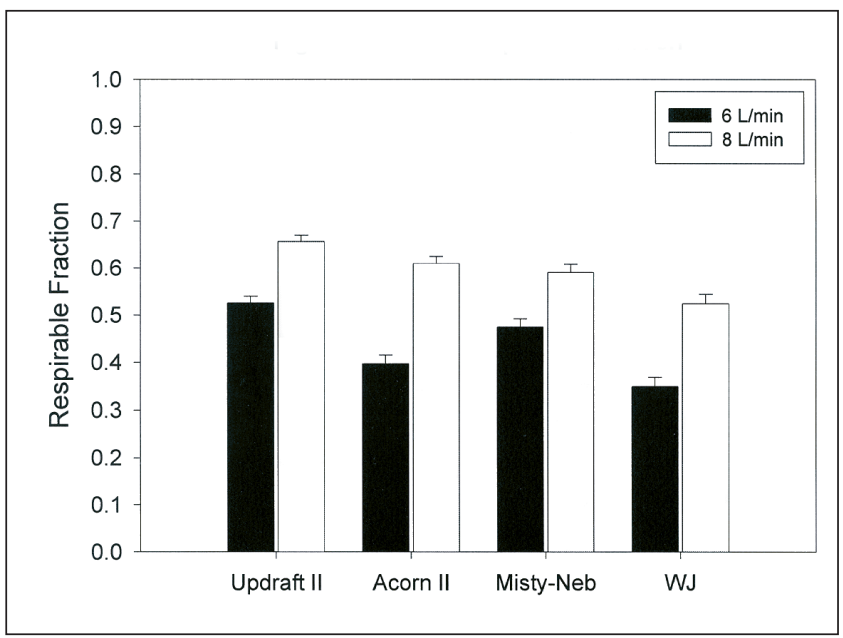

Figure 2) Mean respirable fraction within a $95 \%$ CI at flows of 6 and $8 \mathrm{~L} / \mathrm{min}$ for each type of nebulizer. WJ Whisper Jet nebulizer (Marquest, Englewood, Colorado)

tient respiratory activity, it was assumed that for most patients (excluding any small child with a mean inspiratory flow that was less than the driving flow of the nebulizer), all the aerosol generated would be inhaled during inspiration and that it was wasted during expiration. Hence, using a respiratory muscle 'duty cycle' (26) of 0.43 (average duty cycle measured in 43 pediatric CF patients [27]), more than half of the output was lost. Estimated pulmonary drug deposition $\left(\mathrm{D}_{\mathrm{E}}\right)$ was the product of the duty cycle and the $\mathrm{O}_{\mathrm{RF}}$.

$$
\mathrm{D}_{\mathrm{E}}=0.43 \times \mathrm{O}_{\mathrm{RF}}
$$

Because nebulizer efficiency is directly related to $D_{E}$, the cost analysis was based on the $\mathrm{D}_{\mathrm{E}}$ that could be accomplished when using each of the four types of nebulizers and included the aforementioned costs. The total cost of aerosol drug delivery was prorated by calculating the cost of the additional drug and therapist time required when using the least efficient nebulizers in order to achieve the same $\mathrm{DE}_{\mathrm{E}}$ attainable in a single aerosol treatment when using the most efficient nebulizer. These additional costs were calculated using an efficiency factor derived for each nebulizer at both 6 and $8 \mathrm{~L} / \mathrm{min}$.

The efficiency factor was the $\mathrm{D}_{\mathrm{E}}$ of the most efficient nebulizer divided by the $\mathrm{DE}_{\mathrm{E}}$ of the nebulizer in question where the efficiency factor for the most efficient nebulizer was 1.00

\section{RESULTS}

The efficiency was both flow and device dependent. The Updraft II was consistently the most efficient nebulizer, while the WJ was consistently the least efficient. This is illustrated in Figure 1, which include means and 95\% CIs. The Updraft II demonstrated a 1.6- to twofold greater efficiency, at flows of 8 and $6 \mathrm{~L} / \mathrm{min}$, respectively, than that of the WJ. The differences between the Misty-Neb or the Acorn II and the Updraft II were not large, but all three types of nebulizers were strikingly more efficient than the WJ. In all four nebulizers, the efficiency of each device was less when using $4 \mathrm{~mL}$ of saline only compared with the efficiency of the same device when using a $4 \mathrm{~mL}$ solution of medication and saline.

Although the particle size distribution depended on both the device and flow, it was independent of the various nebulizing solutions tested. Therefore, the data for RF of the different nebulizing solutions were combined for each individual nebulizer type (Figure 2). Values for $V_{D}$ were both device and solution dependent but independent of flow; thus, data for both flows were pooled. Figure 3 illustrates the mean $V_{D}$ for each nebulizer and for each nebulizing solution. $V_{D}$ 
was higher for saline than for the $4 \mathrm{~mL}$ medication charges, which were virtually identical.

When the mean $R F$ and $V_{D}$ values for each nebulizer are compared, the Updraft II produced the highest mean RF and a low mean $\mathrm{V}_{\mathrm{D}}$, while the $\mathrm{WJ}$ produced the lowest mean $\mathrm{RF}$ and the highest mean $\mathrm{V}_{\mathrm{D}}$. The recorded nebulization times are listed in Table 1. In this aspect, the Updraft II proved to have the best performance.

The calculated $\mathrm{DE}_{\mathrm{E}}$ for each nebulizer was also a reflection of its efficiency. The Updraft II yielded the largest $\mathrm{D}_{\mathrm{E}}$ for each drug trial, while the $\mathrm{WJ}$ consistently yielded the lowest. Although the Misty-Neb had the lowest unit cost per nebulizer, it was the Updraft II that demonstrated the most costeffectiveness overall because of its efficiency and shorter nebulization times. In assessing the total cost for a single aerosol treatment, the $\mathrm{WJ}$ proved to be the most expensive nebulizer to use, while delivering the least medication. Table 1 presents the cost analysis and includes labour costs of a respiratory therapist (at an average hourly wage of $\$ 23.00$ ), and the mean nebulization times of each nebulizer as listed in Table 2.

The prorated costs are provided in Table 3. The costs for additional salbutamol and tobramycin are not shown in the table but are included in the listed prorated total costs. The potential for cost savings can be seen by comparing the cost of using the Updraft II and the WJ. It would be necessary to administer two consecutive aerosol treatments using the $\mathrm{WJ}$ nebulizer at a flow of $6 \mathrm{~L} / \mathrm{min}$ to deliver the same amount of medication to the lungs without increasing the dosage to achieve the same pulmonary dose in a single aerosol treat-

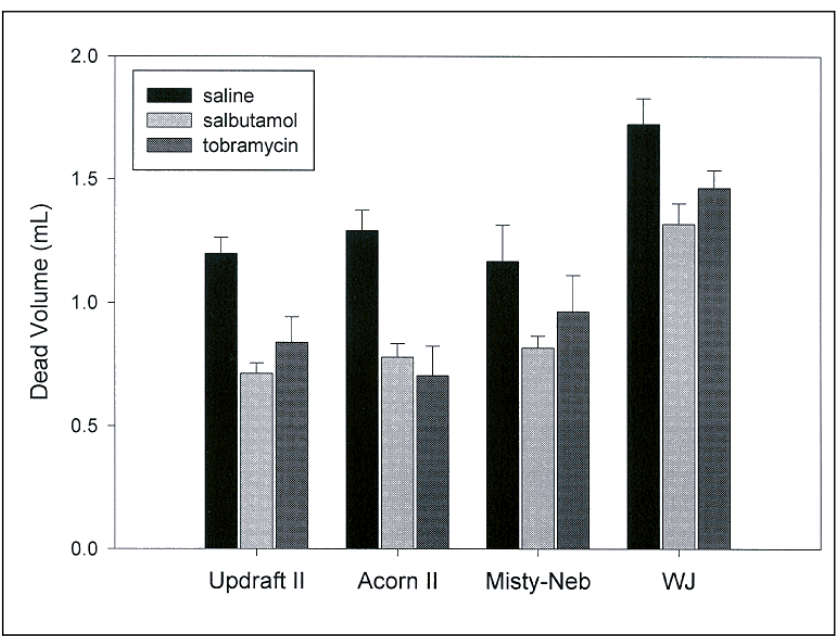

Figure 3) Combined mean dead volume within a 95\% CI for both 6 and $8 \mathrm{~L} / \mathrm{min}$ using $4 \mathrm{~mL}$ of saline, and the $4 \mathrm{~mL}$ charges of salbutamol and tobramycin. WJ Whisper Jet nebulizer (Marquest, Englewood, Colorado)

ment when using the Updraft II nebulizer. The extra cost incurred to administer two consecutive treatments of salbutamol or tobramycin increases the total cost to $\$ 14.96$ and $\$ 21.56$, respectively. In all cases, the material cost of the nebulizer represented only a small fraction of the total cost.

Table 4 shows a comparison of the particle size measurements made in the laboratory to the manufacturer specifications. No other data comparisons could be made with the manufacturer data because values for $\mathrm{V}_{\mathrm{D}}, \mathrm{RF}$ and output were not available. Wide discrepancies exist between the

TABLE 1

Cost analysis

\begin{tabular}{|c|c|c|c|c|c|c|c|c|}
\hline & & $\begin{array}{l}\text { Material } \\
\text { cost }(\$)\end{array}$ & $\begin{array}{c}D_{E} \text { at } \\
6 \mathrm{~L} / \mathrm{min}(\mathrm{mg})\end{array}$ & $\begin{array}{l}\text { Labour } \\
\text { cost (\$) }\end{array}$ & $\begin{array}{c}\text { Total cost } \\
\text { (\$) }\end{array}$ & $\begin{array}{c}D_{E} \text { at } \\
8 \mathrm{~L} / \mathrm{min}(\mathrm{mg})\end{array}$ & $\begin{array}{l}\text { Labour } \\
\text { cost (\$) }\end{array}$ & $\begin{array}{c}\text { Total cost } \\
\text { (\$) }\end{array}$ \\
\hline \multirow[t]{4}{*}{ Salbutamol $(2.5 \mathrm{mg})$} & Updraft II & 0.87 & 0.38 & 5.29 & 6.16 & 0.51 & 4.03 & 4.90 \\
\hline & Acorn II & 1.06 & 0.28 & 6.71 & 7.77 & 0.44 & 4.95 & 6.01 \\
\hline & Misty-Neb & 0.77 & 0.32 & 6.98 & 7.75 & 0.42 & 4.83 & 5.60 \\
\hline & WJ & 1.00 & 0.19 & 6.90 & 7.90 & 0.29 & 4.79 & 5.79 \\
\hline \multirow[t]{4}{*}{ Tobramycin $(80 \mathrm{mg})$} & Updraft II & 3.61 & 12.07 & 5.21 & 8.82 & 15.26 & 4.29 & 7.90 \\
\hline & Acorn II & 3.80 & 8.22 & 7.17 & 10.97 & 14.74 & 5.64 & 9.44 \\
\hline & Misty-Neb & 3.51 & 10.33 & 6.63 & 10.14 & 12.67 & 4.60 & 8.11 \\
\hline & WJ & 3.74 & 5.50 & 6.56 & 10.30 & 9.19 & 3.95 & 7.69 \\
\hline
\end{tabular}

Average wage for a respiratory therapist is $\$ 23.00 / \mathrm{h}$. Dose cost for salbutamol $\$ 0.16$ and tobramycin $\$ 2.90$. Unit cost of the Updraft II (Hudson, Temecula, California) is \$0.71, Acorn II nebulizer (Marquest, Englewood, Colorado) \$0.90, Misty-Neb nebulizer (Baxter Healthcare Corporation, Valencia, California) \$0.61 and Whisper Jet nebulizer (Marquest, Englewood, Colorado) (WJ) \$0.84. DE Estimated pulmonary drug deposition

TABLE 2

Mean nebulization times

\begin{tabular}{lcccccccr}
\hline & \multicolumn{2}{c}{ Updraft II } & \multicolumn{2}{c}{ Acorn II } & \multicolumn{2}{c}{ Misty-Neb } & \multicolumn{2}{c}{ WJ } \\
& $\mathbf{6 ~ L / m i n}$ & $\mathbf{8 ~ L / m i n}$ & $\mathbf{6 ~ L / m i n}$ & $\mathbf{8 ~ L / m i n}$ & $\mathbf{6 ~ L / m i n}$ & $\mathbf{8 ~ L / m i n}$ & $\mathbf{6 ~ L / m i n ~}$ & $\mathbf{8 ~ L / m i n ~}$ \\
\hline Saline & $10.5 \pm 0.9$ & $8.7 \pm 0.4$ & $14.3 \pm 0.7$ & $10.8 \pm 0.5$ & $13.7 \pm 0.9$ & $11.4 \pm 1.4$ & $12.9 \pm 1.2$ \\
Salbutamol & $13.8 \pm 1.7$ & $10.5 \pm 0.9$ & $17.5 \pm 0.8$ & $12.9 \pm 0.6$ & $18.2 \pm 0.8$ & $12.6 \pm 0.9$ & $18 \pm 3.7$ & $12.5 \pm 1.1$ \\
Tobramycin & $13.6 \pm 1.1$ & $11.2 \pm 1.4$ & $18.7 \pm 1.3$ & $14.7 \pm 0.6$ & $17.3 \pm 0.9$ & $12.0 \pm 1.8$ & $17.1 \pm 1.6$ & $10.3 \pm 1.2$ \\
\hline
\end{tabular}

Mean time in minutes with standard deviation ( $n=6)$. Acorn II nebulizer (Marquest, Englewood, Colorado); Misty-Neb nebulizer (Baxter Healthcare Corporation, Valencia, California); Whisper Jet nebulizer (Marquest, Englewood, Colorado) (WJ); 1730 Updraft II nebulizer (Hudson, Temecula, California) 
TABLE 3

Calculation of the cost of aerosol administration when attempting to achieve the same estimated pulmonary drug deposition attained when using the Hudson Updraft II nebulizer (Hudson, Temecula, California)

\begin{tabular}{llcccc}
\hline & & Factor at 6 L/min & Total cost (\$) & Factor at 8 L/min & Total cost (\$) \\
\hline Salbutamol (2.5 mg) & Updraft II & 1.00 & 6.16 & 1.00 & 4.90 \\
& Acorn II & 1.36 & 10.24 & 1.16 & 6.83 \\
& Misty-Neb & 1.19 & 9.11 & 1.21 & 6.65 \\
Tobramycin (80 mg) & WJ & 2.00 & 14.96 & 1.78 & 9.65 \\
& Updraft II & 1.00 & 8.82 & 1.00 & 7.90 \\
& Acorn II & 1.47 & 15.70 & 1.04 & 9.78 \\
& Misty-Neb & 1.17 & 11.76 & 1.20 & 1.66 \\
\hline
\end{tabular}

The factor at 6 and $8 \mathrm{~L} / \mathrm{min}$ has been calculated relative to the estimated pulmonary drug deposition of the Updraft II for salbutamol and tobramycin. In order to deliver the same amount of each drug when using the other three nebulizers, additional drug and administration time would be necessary. Using the factors listed above the total cost of deliver when using the other nebulizers was calculated as: Total cost = Factor $x$ (Original labour cost + original drug cost) + cost of the nebulizer. Acorn II nebulizer (Marquest, Englewood, Colorado); Misty-Neb nebulizer (Baxter Healthcare Corporation, Valencia, California); Whisper Jet nebulizer (Marquest, Englewood, Colorado) (WJ); 1730 Updraft II nebulizer (Hudson, Temecula, California) WJ Whisper Jet nebulizer (Marquest, Englewood, Colorado) (WJ)

\section{TABLE 4}

\section{Comparison of measured particle size to manufacturer specifications from four nebulizers}

Hudson 1730 Updraft II Baxter Misty-Neb Marquest Whisper Jet Marquest Acorn II

\begin{tabular}{|c|c|c|c|c|}
\hline \multicolumn{5}{|l|}{ Manufacturer data* } \\
\hline $\begin{array}{l}\text { Mass median aerodynamic diameter }(\mu \mathrm{m}) \\
\text { at low flow }\end{array}$ & 2.3 & & 8.8 & 4.9 \\
\hline $\begin{array}{l}\text { Mass median aerodynamic diameter }(\mu \mathrm{m}) \\
\text { at high flow }\end{array}$ & 2.1 & 3.56 & 0.98 & 0.89 \\
\hline \multicolumn{5}{|l|}{ Current study ${ }^{\dagger}$} \\
\hline MMD $(\mu \mathrm{m})$ at low flow & $4.78(4.63,4.93)$ & & $8.89(8.30,9.48)$ & $9.08(8.41,9.75)$ \\
\hline MMD $(\mu \mathrm{m})$ at high flow & $3.77(3.64,3.90)$ & $5.30(4.95,5.65)$ & $4.03(3.82,4.24)$ & $3.70(3.56,3.84)$ \\
\hline \multicolumn{5}{|c|}{ Testing parameters used in current study and for manufacturer data } \\
\hline Flow (L/min) & 6 and 8 & 7 & 4 and 10 & 4 and 10 \\
\hline Nebulized solutions & Saline & $\begin{array}{l}\text { Methylene blue in } \\
\text { sterile water }\end{array}$ & Saline & Saline \\
\hline
\end{tabular}

${ }^{*}$ Particle sizing by cascade impaction; ${ }^{\dagger}$ Particle sizing by laser diffraction. Shows mean with $95 \%$ confidence limits $n=6$. MMD Mass Median diameter

laboratory data and those data provided by the manufacturers of individual nebulizers. Where indicated in Table 4, the manufacturer has provided the mass median aerodynamic diameter (MMAD) because cascade impaction was employed for particle sizing.

\section{DISCUSSION}

This study demonstrates that four commonly used disposable jet nebulizers were clearly different in efficiency and performance, and it has shown that the data provided by each manufacturer are insufficient to evaluate the efficiency of a device. We assessed nebulizer performance by examining the $\mathrm{V}_{\mathrm{D}}$ of each nebulizer, $\mathrm{RF}$ generated, $\mathrm{O}_{\mathrm{RF}}$ and time required for each nebulizer to reach the end of nebulization. The Hudson 1730 Updraft II consistently outperformed the other three devices. In contrast, the Marquest WJ's performance ranked the lowest. Our cost analysis has shown that the cost of drug delivery is directly dependent upon the efficiency of the nebulizer rather than the unit cost of the device. If the differences in the nebulizing flow are considered, the particle size distributions observed were in keeping with other studies $(14,28)$. While the calculation of expected $D_{E}$ was based upon specific assumptions, these assumptions were the same for each device so, even if not absolutely correct, they would not change the relative advantages of one device compared with another.

For the purpose of this investigation, as in keeping with other studies $(1,6,18,19), 30 \mathrm{~s}$ without aerosol production was identified as end nebulization. In the trials using the Updraft II, the generation of intermittent aerosol was limited, and, thus, it was easy to assess this endpoint. This was not true of the other three nebulizers, which produced an intermittent output for a prolonged period of time before reaching dryness. Had a shorter time interval been required, for example, $10 \mathrm{~s}(2,3)$, the endpoint for the Misty-Neb, WJ and the Acorn II would have been reached sooner, and the calculated output for each nebulizer would have been less than the values actually recorded. However, the output values for the Updraft II in this case would have been minimally affected. We have avoided performing rigorous statistical analyses in this study because the small differences observed in some of the data may have achieved statistical significance due to the small standard deviations in the data while having no clinical significance. Data are presented with the $95 \%$ CIs so that cli- 
nicians may judge for themselves the significance of the results reported here to their practice.

This is not the first study to illustrate the in vitro differences in nebulizer performance, but it is unique in demonstrating the impact of the $V_{D}$ on the efficiency of a device with regards to total nebulized drug output when the effect of evaporative losses are taken into consideration. The RF observed for the four devices is within the range reported in previous studies $(14,15,19,29)$. Hess et al $(6)$ reported $V_{D}$ data, unfortunately nebulizer specific comparisons were not possible because the data in this study were pooled for all nebulizer types for different flow and volume settings. Weber et al (15) stated that the $V_{D}$ was consistently between 1 and $2 \mathrm{~mL}$ for the jet nebulizers that they tested; however, data were not shown and no direct comparisons could be made. Other attempts at direct comparison between the existing performance data in the literature proved difficult because conditions such as particle size measurement technique, fill volume, nebulizing agent, driving gas source and flow varied from study to study, and data on $V_{D}$ were rarely available (30).

The combination of a nebulizer's $V_{D}$ and its particle size distribution ultimately determine its efficiency. $V_{D}$ is inversely proportional to the output of a nebulizer, while the $\mathrm{RF}$, as determined by the particle size distribution, is directly proportional to the output that is available for pulmonary deposition. Factors such as surface tension and charge volume can affect the inherent $V_{D}$ of a device and, thus, alter its efficiency. A nebulizing solution with a lower surface tension results in a smaller $V_{D}(2,3)$, while using a larger charge volume ( $4 \mathrm{~mL}$ or more instead of $3 \mathrm{~mL}$, for example) results in a lower concentration of drug in the $\mathrm{V}_{\mathrm{D}}(6,11)$. Both of these factors result in a greater and more efficient aerosolized drug output. Our results indicate that the efficiency of saline output parallels the efficiency of drug output when using a 4 $\mathrm{mL}$ charge volume; however, it was lower in all four nebuliz-

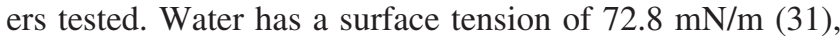
and the surface tension of saline is similar, but when mixed with medications, surface tension may differ depending upon the concentration and the specific properties of that agent. Coates et al (3) and Hurley et al (19) have found the surface tension of a $4 \mathrm{~mL}(20 \mathrm{mg} / \mathrm{mL})$ solution of tobramycin and saline to be $66 \mathrm{mN} / \mathrm{m}$ and $54 \mathrm{mN} / \mathrm{m}$, respectively. A study by MacNeish et al (2) compared two different salbutamol preparations, and demonstrated that the preparation with a surface tension similar to that of water yielded a lower nebulized salbutamol output. Thus, using saline as a proxy for medication is not appropriate to judge the efficiency of a nebulizer when administering a specific agent. The evaluation of efficiency should include the device, the source of the nebulizing gas flow in combination with the drug and the dilutant intended for nebulization.

Manufacturer performance specifications for nebulizers usually include only particle size data (MMAD), often generated by nebulizing saline and measured by cascade impaction. These data should be reviewed with caution because measurements made by cascade impaction are very dependent on the flow and relative humidity of the gas used to draw the aerosol into the impactor. Thus, drying of the droplets occurs and results in an artificially small particle size (24). This may explain some of the discrepancies between our data and those of the manufacturers. Furthermore, no values for measured $V_{D}$ or output have been quoted, resulting in very little information on which to base decisions about the appropriate nebulizers to use.

Our data indicate that a change from a less efficient (Misty-Neb, Acorn II and WJ) to a more efficient nebulizer such as the Updraft II can increase the pulmonary availability of a drug by more than twofold without increasing the frequency or the dose of the medication; at the same time, it can potentially be a source of cost savings for an institution. The prorated costs in Table 3 may seem somewhat artificial because it may be more practical to simply increase the initial dose of an inexpensive drug when using the less efficient nebulizers. However, drug dosage is rarely based on nebulizer performance. In clinical practice where the frequency of administration of a drug such as salbutamol is dependent upon the clinical response to the drug, using a low efficiency nebulizer may result in less deposition, and, thus, an increased frequency of administration may be necessary to achieve the desired clinical response. There is evidence in the literature that demonstrates the clinical impact of using a greater efficiency nebulizer over a device with lower efficiency (13). For a drug such as tobramycin where the clinical response to treatment is not immediate, using a low efficiency nebulizer may result in suboptimal pulmonary levels. Furthermore, changing the practice from face mask to mouthpiece aerosol administration would result in a further twofold increase in pulmonary deposition (32). Our results suggest that labour costs far outweight the cost of medication; however, the agents in question are relatively inexpensive. With other drugs such as the new preparation of tobramycin (TOBI), rhDNase or colistin, which are being proposed for the treatment of $\mathrm{CF}$, the cost of the medication alone may exceed the other costs, and, in these cases, using the most efficient nebulizer will be of utmost importance.

\section{CONCLUSIONS}

This study has shown that proper cost analysis of aerosol therapy should include the cost of the medication, the unit cost of the nebulizer, labour costs and, most important, the output efficiency of the nebulizer. Manufacturer specifications of nebulizer performance are insufficient to predict the efficiency of a device because proper evaluation depends upon the accurate measurement of drug output, which must include measurement of the $\mathrm{V}_{\mathrm{D}}$, changes in concentration of the solution during nebulization and accurate particle size analysis. Unfortunately, $\mathrm{V}_{\mathrm{D}}$ is rarely reported despite its major role in determining nebulizer efficiency. A corollary of these findings is that caution must be exercised when interpreting studies that use different jet nebulizers. For example, in previous clinical trials (33-38), where several different nebulizing systems were approved for use (39) to evaluate a standardized dose of $2.5 \mathrm{mg}$ of rhDNase, the 
variablity in outcome may have been attributed, at least in part, to the different levels of pulmonary deposition attained by different conventional nebulizers and a breath-enhanced nebulizer. Standardization of the performance of aerosol administration systems is necessary to allow clinicians to specify the device to be used when prescribing a specific drug dose.

ACKNOWLEDGEMENTS: We thank Eli Lilly Canada Inc for their generous supply of Nebcin, and Trudell Medical Marketing Limited (London, Ontario) and VitalAire Healthcare (Mississauga) for providing nebulizers for this study.

\section{REFERENCES}

1. Newman SP, Pellow PGD, Clay MM, Clarke SW. Evaluation of jet nebulisers for use with gentamycin solution. Thorax s1985;40:671-6.

2. MacNeish CF, Meisner D, Thibert R, Kelemen S, Vadas EB, Coates AL. A comparison of pulmonary availability between Ventolin (albuterol) nebules and Ventolin (albuterol) respirator solution. Chest 1997; 111:204-8.

3. Coates AL, MacNeish CF, Meisner D, et al. The choice of jet nebulizer, nebulizing flow and the addition of Ventolin Respiratory Solution affects tobramycin aerosols used in cystic fibrosis. Chest 1997;111:1206-12.

4. Newhouse MT. In vitro "respirable mass" (RM) has no clinical relevance. Am J Respir Crit Care Med 1997;155:A667. (Abst)

5. O'Callaghan C, Clarke AR, Milner AD. Inaccurate calculation of drug output from nebulisers. Eur J Pediatr 1989;148:473-4.

6. Hess D, Fisher D, Williams P, Pooler S, Kacmarek RM. Medication nebulizer performance: Effects of diluent volume, nebulizer flow and nebulizer brand. Chest 1996;110:498-505.

7. Langford SA, Allen MB. Salbutamol output from two jet nebulizers. Respir Med 1993;87:99-103.

8. Schöni MH, Kraemer R. Osmolarity changes in nebulizer solutions. Eur Respir J 1989;2:887-92.

9. Coates AL, MacNeish CF, Lands LC, et al. Factors influencing the rate of drug output during the course of wet nebulization. J Aerosol Med 1998;11:101-11.

10. Phipps PR, Gonda I. Droplets produced by medical nebulizers - some factors affecting their size and solute concentration. Chest 1990;97:1327-32.

11. Wood JA, Wilson RSE, Bray C. Changes in salbutamol concentration in the reservoir solution of a jet nebulizer. Br J Dis Chest 1986;80:164-9.

12. Coates AL, MacNeish CF, Lands LC, Meisner D, Kelemen S, Vadas EB. A comparison of the availability of tobramycin for inhalation from vented versus unvented nebulizers. Chest 1998;113:951-6.

13. Newnham DM, Lipworth BJ. Nebuliser performance, pharmokinetics, airways and systemic effects of salbutamol given via a novel nebuliser delivery system ("Ventstream"). Thorax 1994;49:762-70.

14. Loffert DT, Ikle D, Nelson HS. A comparison of commercial jet nebulizers. Chest 1994;106:1788-92.

15. Weber A, Morlin G, Cohen M, Williams-Warren J, Ramsey BW, Smith AL. Effect of nebulizer type and antibiotic concentration on device performance. Pediatr Pulmonol 1997;23:249-60.

16. The Health Care and Environment Sector Board. Respiratory therapy equipment, Part 3 Specification for gas-powered nebulizers for the delivery of drugs. BS 7711 Part 3, 1-9. 1994. London: British Standards Institution, 1994.

17. MacLusky IB, Gold R, Corey ML, Levison H. Long-term effects of inhaled tobramycin in patients with cystic fibrosis colonized with Pseudomonas aeruginosa. Pediatr Pulmonol 1989;7:42-8.

18. Clay MM, Pavia D, Newman SP, Lennard-Jones T, Clarke SW. Assessment of jet nebulisers for lung aerosol therapy. Lancet 1983;ii:592-4.

19. Hurley PK, Smye SW, Cunliffe H. Assessment of antibiotic aerosol generation using commercial jet nebulizers. J Aerosol Med 1994;7:217-28

20. Cockcroft DW, Hurst TS, Gore BP. Importance of evaporative water losses during standardized nebulized inhalation provocation tests. Chest 1989;96:505-8.

21. Gonda I. Aerosols for delivery of therapeutic and diagnostic agents to the respiratory tract. Crit Rev Therap Drug Carrier Sys 1990;6:273-313.

22. Newman SP, Pavia D. Aerosol deposition in man. In: Moren F Newhouse MT, Dolovich MB, eds. Aerosols in Medicine: Principles, Diagnosis and Therapy. Oxford: Elsevier Science, 1985:193-217 [7].

23. Kwong E, MacNeish CF, Meisner D, Kelemen S, Vadas EB, Coates AL. The use of osmometry as a means of determining changes in drug concentration during jet nebulization. J Aerosol Med 1998; 11:89-100.

24. Clark AR. The use of laser diffraction for the evaluation of the aerosol clouds generated by medical nebulizers. Int J Pharm 1995;115:69-78.

25. O'Callaghan C, Barry PW. The science of nebulised drug delivery. Thorax 1997;52:S31-44.

26. Milic-Emili J, Grunstein M. Drive and timing of components of ventilation. Chest 1976;70:131-3.

27. Coates AL, MacNeish CF, Allen PD, Lands LC. Physiological factors influencing expected pulmonary deposition of tobramycin in cystic fibrosis. Pediatr Pulmonol 1998;26(Suppl 17). (Abst A257)

28. Finlay WH, Stapleton KW, Zuberbuhler P. Variations in predicted regional lung deposition of salbutamol sulphate between 19 nebulizers. J Aerosol Med 1998;11:65-80.

29. Dennis JH. Drug nebuliser design and performance: Breath Enhanced Jet Vs. Constant Output Jet vs Ultrasonic. J Aerosol Med 1995;8:277-80.

30. Coates AL, Ho SL. Drug administration by jet nebulization: State of the art. Pediatr Pulmonol 1998;26:412-23.

31. McCallion ONM, Taylor KMG, Thomas M, Taylor AJ. Ultrasonic nebulisation of fluids with different viscosities and surface tensions. J Aerosol Med 1995;8:281-4.

32. Chua HL, Collis GG, Newbury AM, et al. The influence of age on aerosol deposition in children with cystic fibrosis. Eur Respir J 1994;7:2185-91.

33. Ramsey BW, Astley SJ, Aitken ML, et al. Efficacy and safety of short-term administration of aerosolized recombinant human deoxyribonuclease in patients with cystic fibrosis. Am Rev Respir Dis 1993;148:145-51.

34. McCoy K, Hamilton S, Johnson C for the Pulmozyme Study Group. Effects of 12-week administration of dornase alfa in patients with advanced cystic fibrosis lung disease. Chest 1996;110:889-95.

35. Fuchs HJ, Borowitz DS, Christiansen DH, et al. Effect of aerosolized recombinant human DNase on exacerbations of respiratory symptoms and on pulmonary function in patients with cystic fibrosis. N Engl J Med 1994;331:637-42.

36. Hubbard RC, McElvaney NG, Birrer P, et al. A preliminary study of aerosolized recombinant human deoxyribonuclease $\mathrm{I}$ in the treatment of cystic fibrosis. N Engl J Med 1992;326:812-5.

37. Wilmott RW, Amin RS, Colin AA, et al. Aerosolized recombinant human DNase in hopitalized cystic fibrosis patients with acute pulmonary exacerbations. Am J Respir Crit Care Med 1996;153:1914-7.

38. Davies J, Trindade M-T, Wallis C, Rosenthal M, Crawford O, Bush A. Retrospective review of the effects of rhDNase in children with cystic fibrosis. Pediatr Pulmonol 1997;23:243-8.

39. Ramsey BW, Dorkin HL. Consensus conference: Practical implications of Pulmozyme. September 22, 1993. Pediatr Pulmonol 1994;17:404-8. 


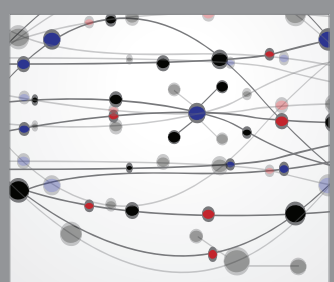

The Scientific World Journal
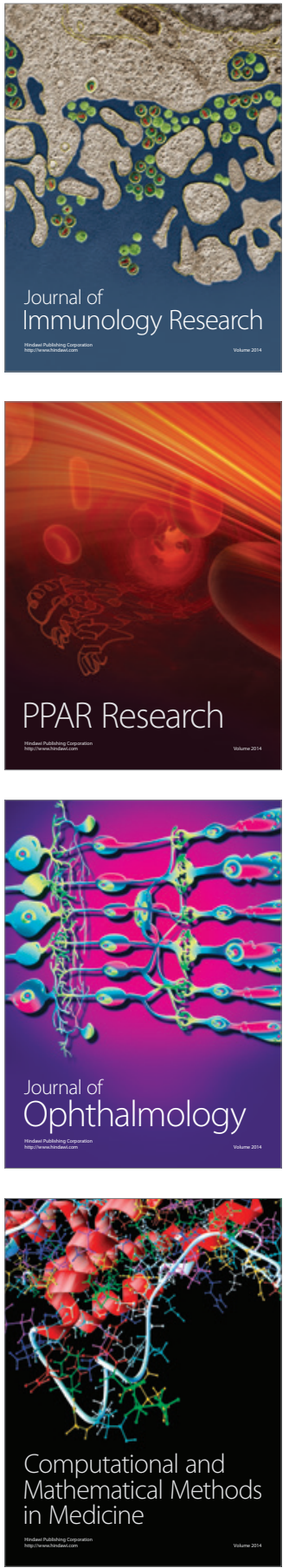

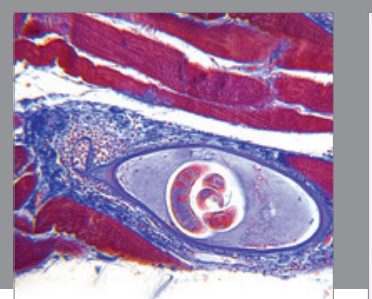

Gastroenterology Research and Practice

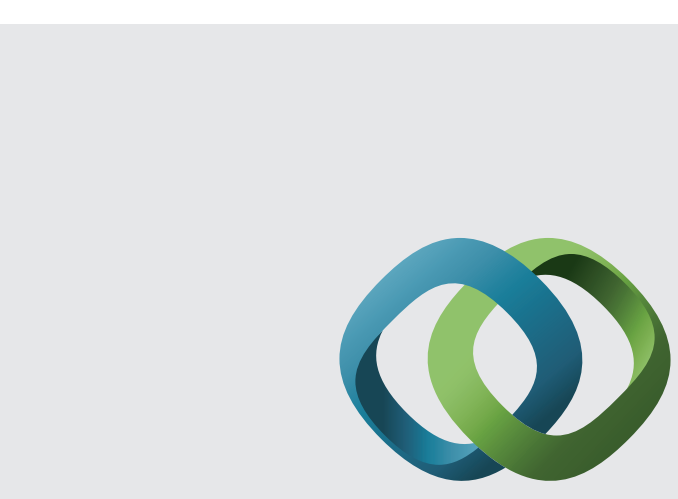

\section{Hindawi}

Submit your manuscripts at

http://www.hindawi.com
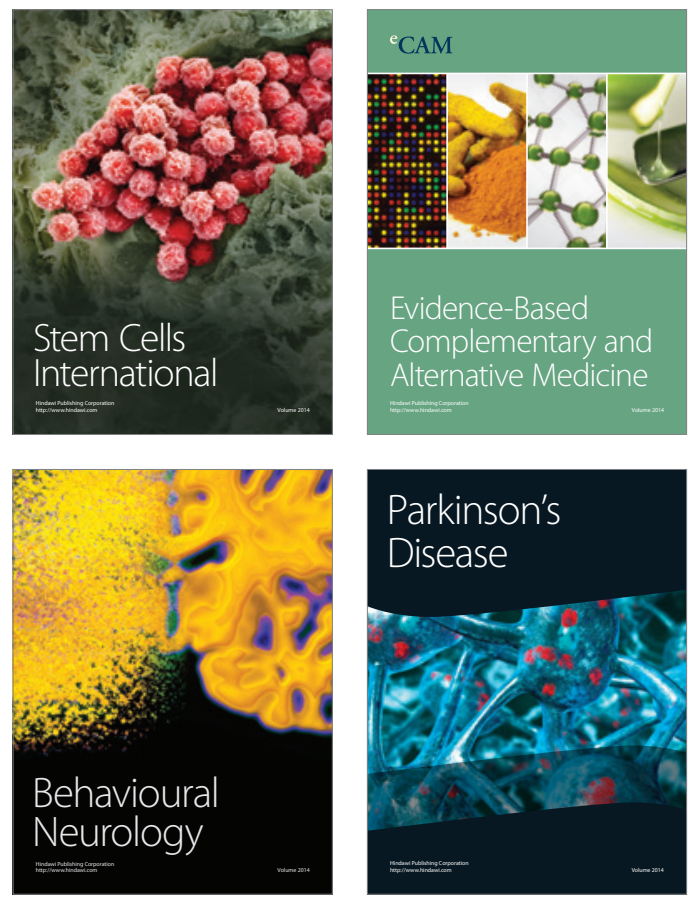
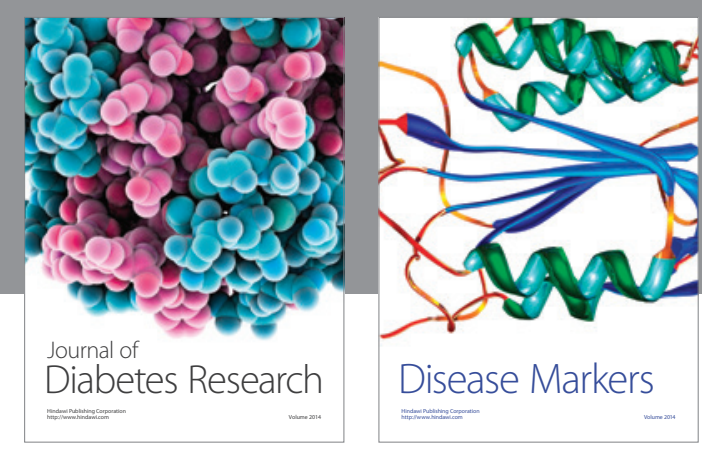

Disease Markers
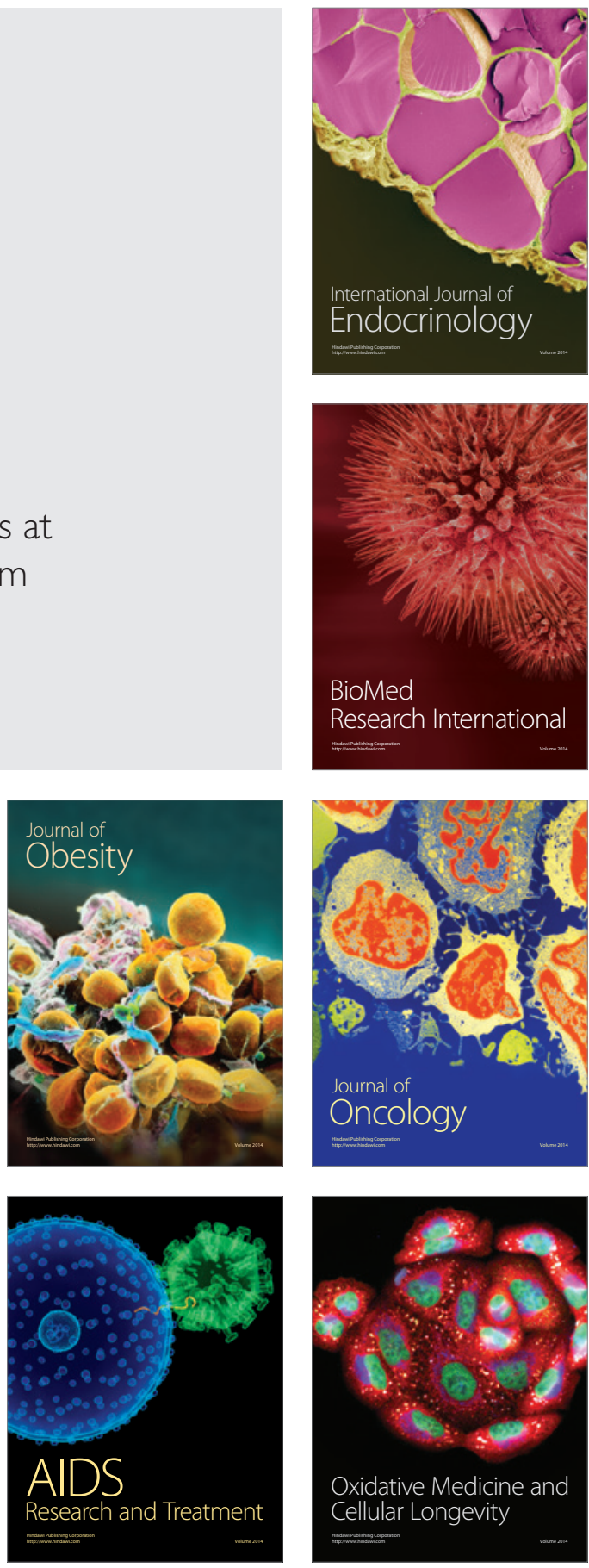